\title{
Opioid therapy for chronic non-cancer pain: guidelines for Hong Kong
}

\author{
CW Cheung *, Timmy CW Chan, PP Chen, MC Chu, William CM Chui, PT Ho, Flori Lam, SW Law, \\ Josephine LY Lee, Steven HS Wong, Vincent KC Wong
}

\begin{abstract}
A B S T R A C T
Opioids are increasingly used to control chronic non-cancer pain globally. International opioid guidelines have been issued in many different countries but a similar document is not generally available in Hong Kong. Chronic opioid therapy has a role in multidisciplinary management of chronic non-cancer pain despite insufficient evidence for its effectiveness and safety for long-term use. This document reviews the current literature to inform Hong Kong practitioners about the rational use of chronic opioid therapy in chronic non-cancer pain. It also aims to provide useful recommendations for the appropriate, effective, and safe use of such therapy in the management of chronic non-cancer pain in adults. Physicians should conduct a comprehensive biopsychosocial evaluation of patients prior to the commencement of opioid therapy. When opioid use is deemed appropriate, the patient should provide informed consent within an agreement that specifies treatment goals and expectations. A trial of opioid can be commenced and, provided there is progress towards treatment goals, then chronic therapy can be considered at a dose that minimises harm. Monitoring of effectiveness, safety, and drug misuse should be continued. Treatment should be stopped when opioids become ineffective, intolerable, or misused. The driving principles for opioid prescription in chronic pain management should be: start with a low dose, titrate slowly, and maintain within the shortest possible time.
\end{abstract}

\section{Hong Kong Med J 2016;22:496-505}

DOI: $10.12809 / \mathrm{hkmj} 164920$

${ }^{1}$ CW Cheung *, MD, FHKAM (Anaesthesiology)

${ }^{2}$ TCW Chan, FFPM ANZCA, FHKAM (Anaesthesiology)

${ }^{3}$ PP Chen, FFPM ANZCA, FHKAM (Anaesthesiology)

${ }^{4}$ MC Chu, FFPM ANZCA, FHKAM (Anaesthesiology)

${ }^{5}$ WCM Chui, MSc, BPharm (Hon)

${ }^{6}$ PT Ho, FRCPsych, FHKAM (Psychiatry)

${ }^{7} \mathrm{~F}$ Lam, BHSc(RN)

${ }^{3}$ SW LaW, FRCSEd(Orth), FHKCOS

${ }^{9} \mathrm{JLY}$ Lee, MSc

SHS Wong, MB, BS, FHKAM (Anaesthesiology)

${ }^{5}$ VKC Wong, BCPS, MPharm

1 Laboratory and Clinical Research Institute for Pain, Department of Anaesthesiology, The University of Hong Kong, Pokfulam, Hong Kong 2 Department of Anaesthesiology, Queen Mary Hospital, Pokfulam, Hong Kong

${ }^{3}$ Department of Anaesthesiology and Operating Services, Alice Ho Miu Ling Nethersole Hospital, Tai Po, Hong Kong

${ }^{4}$ Department of Anaesthesia, Pamela Youde Nethersole Eastern Hospital, Chai Wan, Hong Kong

Department of Pharmacy, Queen Mary Hospital, Pokfulam, Hong Kong

${ }^{6}$ Consultation and Liaison Psychiatry Team, Kwai Chung Hospital, Kwai Chung, Hong Kong

${ }^{7}$ Department of Anaesthesiology and Operating Theatre Services, Queen Elizabeth Hospital, Jordan, Hong Kong

${ }^{8}$ Department of Orthopaedics and Traumatology, Prince of Wales Hospital, Shatin, Hong Kong

${ }^{9}$ Occupational Therapy Department, Prince of Wales Hospital, Shatin, Hong Kong

* Corresponding author: cheucw@hku.hk

estimated loss of approximately 0.2 working days per person in the working population per year, and on health care resources, with almost three quarters of respondents consulting a health care practitioner. The latter survey found that reports of chronic pain were strongly associated with co-morbid mental health problems and anxiety. ${ }^{4}$

Opioid therapy is accepted for acute pain and cancer pain, ${ }^{5,6}$ but its effectiveness and safety for chronic non-cancer pain (CNCP) remains contentious. By definition, CNCP refers to nonmalignant pain that lasts beyond the time of tissue healing, or longer than 3 months. ${ }^{1}$ Authors cite weak evidence for opioid use for CNCP due to the lack of randomised controlled trials with long follow-up. ${ }^{7,8}$ Based on systematic reviews, opioids for $\mathrm{CNCP}-$ 
including neuropathic pain, nociceptive pain, and arthritic pain-confer some benefit by reducing pain intensity and improving functional outcome compared with placebo and other non-steroidal anti-inflammatory drugs, ${ }^{9-13}$ but high-quality studies are rare, and treatment duration is short, ranging from 2 weeks to 6 months. A proportion of patients in the studies reviewed did not progress to long-term therapy due to adverse effects. ${ }^{12}$ Discontinuation rates from adverse effects were almost $30 \%$, with the most frequently reported events being constipation, nausea, dizziness, drowsiness, and headache. ${ }^{12}$

The potential to develop opioid abuse or addiction with long-term therapy is also a concern. In studies reviewed, addiction or abuse rates were reported to range from $0.27 \%$ to $0.43 \% .^{12,14,15}$ Deaths related to opioid analgesic overdose have been increasing, and is being linked to an increase in opioid prescriptions for pain. ${ }^{16,17}$ Indeed, chronic opioid exposure from prescription appears to be a strong risk factor for an opioid misuse event in patients just diagnosed with CNCP. ${ }^{18}$ Other potential harm from chronic opioid use includes increased fracture risk, ${ }^{19}$ androgen deficiency, ${ }^{20}$ respiratory depression, ${ }^{21}$ cognitive impairment, ${ }^{22}$ impaired immunity, ${ }^{23}$ and opioid-induced hyperalgesia. ${ }^{24,25}$

Global consumption of opioids for moderateto-severe pain increased approximately 15-fold from 1980 to $2012 .{ }^{26}$ Generally, opioid consumption of countries in Asia, including Hong Kong, is low

\section{香港非癌症慢性疼痛的鴉片類藥物指引}

張志偉、陳智榮、曾煥涁、朱銘知、崔俊明、何培達、 林智穎、羅尚尉、李麗英、黃河山、黃啟宗

使用鴉片類藥物來控制非癌症慢性疼痛越趨普遍。全球多個國家已經 制定有關鴉片類藥物的使用準則, 可是香港並未有類似的指引。儘管 缺乏證據支持長期使用鴉片類藥物的有效性和安全性, 但在跨學科治 理非癌症慢性疼痛方面, 這些藥物確能發揮作用。本文回顧有關合理 使用鴉片類藥物作非癌症慢性疼痛治療的最新文獻, 為香港醫護人員 如何能適當、有效和安全地使用這類藥物在成年患者身上提供建議。 使用這種治療前, 醫生應為患者作全面的生物心理社會評估。如果認 為使用鴉片類藥物作治療是恰當, 應先讓患者簽署同意書列明治療的 目的和期望, 然後才開始嘗試使用鴉片類藥物治療痛症。如果治療達 標, 可緩慢增加劑量至對患者產生最少副作用的最佳目標劑量。治療 過程中應繼續監察藥物的效用和安全性, 避免藥物濫用。假如發現鴉 片類藥物變得無效, 患者未能忍受藥物不良反應或者出現藥物濫用, 便應停止治療。使用鴉片類藥物治療慢性疼痛的準則應是：訂定最低 起始劑量, 再緩慢地增加劑量, 以及儘可能於最短時間內維持劑量。

relative to the global picture $\left(\mathrm{Fig}^{27}\right)$, but showing an increasing trend. ${ }^{27,28}$ Physicians in Hong Kong may be reluctant to prescribe opioids for long-term therapy due to fear of patient addiction. There may also be a cultural prejudice against opioid use stemming

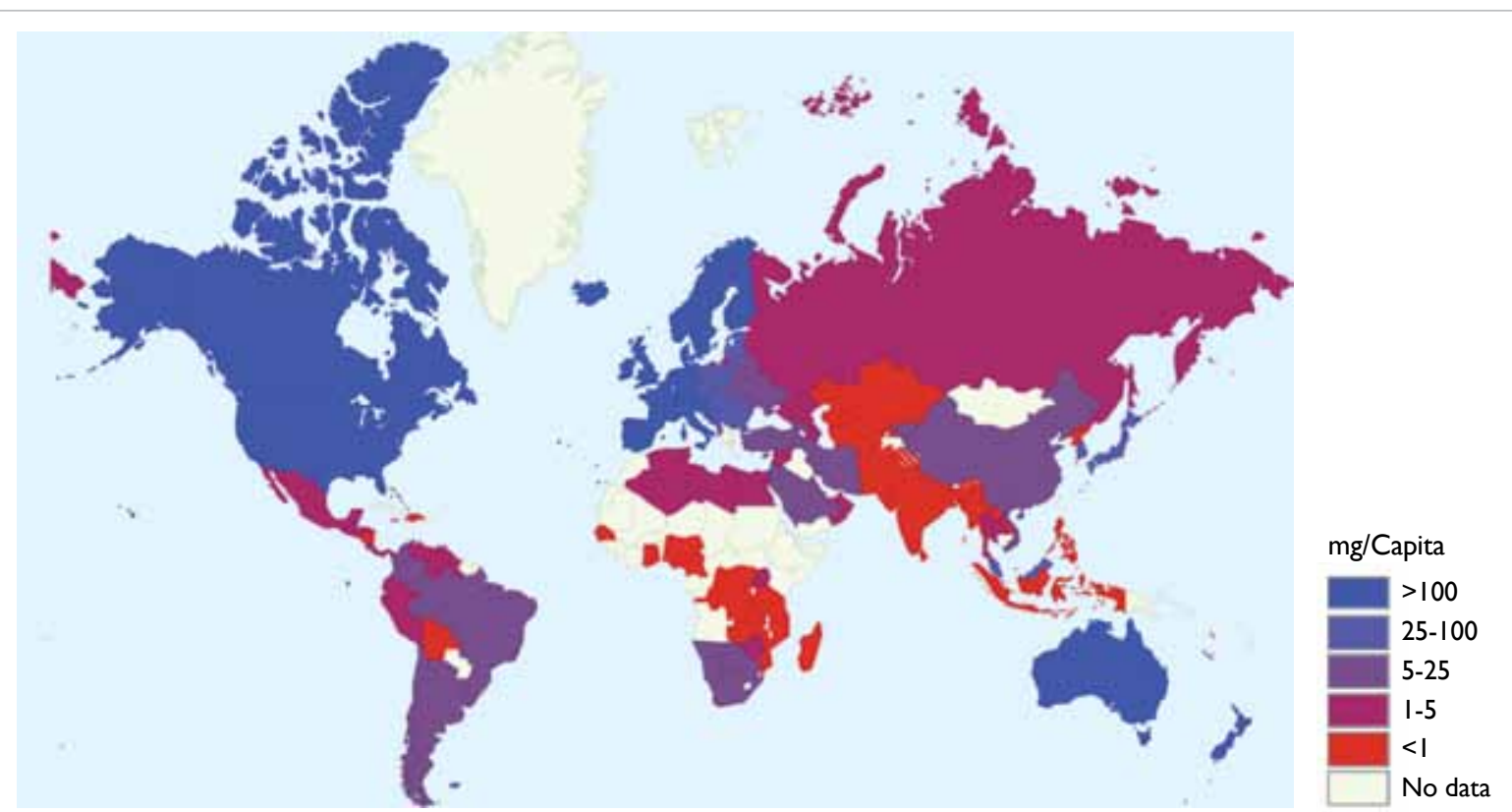

FIG. Global morphine equivalence consumption $(2013)^{27}$

The consumption statistics are displayed in milligrams per capita, which is calculated by dividing the total amount of opioid consumed in kilograms by the population of the country for that particular year (cite United Nations population data). This provides a population-based statistic that allows for comparisons between countries

Reproduced with permission from Pain \& Policy Studies Group. Opioid consumption maps—Morphine equivalence (ME), mg/capita, 2013 
from a history of China's involvement in the global opium trade in the early part of the century. ${ }^{29}$ Other possible barriers to prescription and patient care may include inadequate physician education about pain management, and lack of physician-patient communication about the seriousness of the pain problem. The absence of a central registry for opioid prescriptions, and the limited number of addiction specialists are potential local logistical barriers. With the introduction of opioid choices in Hong Kong, however, the prescription of strong opioids for long-term treatment may become more common. Examples of strong opioids for CNCP used in Hong Kong are listed in Box $1 .^{30}$

Guidelines governing the use of opioids for patients with CNCP have been issued in different countries according to their needs. ${ }^{31-38}$ The Hospital Authority has recently introduced an opioid guideline for $\mathrm{CNCP}$ for public hospital use. A similar guide is not readily available for physicians who are involved in CNCP management but practise outside Hospital Authority in Hong Kong. This document aims to serve as a resource and uniform guide for the appropriate, effective, and safe use of chronic opioid therapy (COT) in the management of CNCP in adults based on local considerations; COT is regarded as the use of strong opioids for more than 3 months. ${ }^{39}$ This guideline provides recommendations about patient selection, risk screening, initiation of COT, and monitoring during COT, based on a review of the current literature. The target audience is all physicians, especially non-pain specialists, and other health care professionals involved in the multidisciplinary management of the patient with $\mathrm{CNCP}$, who are considering prescribing COT.

\section{General considerations for using opioid in patients with chronic non-cancer pain}

The biopsychosocial model describes pain as bodily disruption shaped by an individual's subjective perception. Biological processes, emotions, and social factors all influence the pain experience. ${ }^{2}$ Consequently, chronic pain is a complex condition that requires a multidisciplinary approach to both evaluation and management, preferably in a coordinated treatment programme., ${ }^{40,41}$ The IASP recognises the effectiveness of multidisciplinary pain

BOX I. Strong opioids registered in Hong Kong for chronic pain management ${ }^{30}$

Buprenorphine
Fentanyl
Methadone
Morphine
Oxycodone

Fentanyl

Methadone

Oxycodone

Oxycodone programmes for chronic pain, and recommended the establishment of multidisciplinary pain clinics or pain centres; the latter of which should be associated with a research or academic programme..$^{40}$ Staff at both pain centres and clinics should include practitioners from various disciplines deemed expert in pain management. Physicians, nurses, mental health professionals, and physical therapists are among those who comprise a team that coordinates diagnosis and management, with constant communication, preferably in one setting. ${ }^{40,41}$ Essential elements of multidisciplinary pain programmes address pain management, psychosocial recovery, and physical rehabilitation, and include medication, physical therapy, and cognitive and behavioural strategies. ${ }^{42}$ Such programmes have been proven clinically effective and cost-effective. ${ }^{43-45}$

In fact, COT is just part of the multimodal strategy to manage CNCP. Experts do not recommend opioids for first-line treatment of CNCP. ${ }^{34,36,38}$ Non-opioid treatment options, both non-pharmacological and pharmacological (eg typical analgesics), should be tried first. Despite limited evidence to support the safe and effective use of opioids in CNCP, they may be considered for selected patients who have moderate-to-severe pain and who have not responded adequately to non-opioid therapy. ${ }^{38}$ In accordance with the biopsychosocial model, treatment of CNCP should address the physical, psychological, and social aspects of the pain problem. ${ }^{41}$ Treatment of CNCP should thus aim to reduce pain and support patients' physical, psychological, social, and work functioning. ${ }^{40}$ The goals of COT include pain reduction, reduction of pain-associated symptoms such as anxiety and sleep problems, and improvement of daily function. ${ }^{46,47}$ These goals should be individualised and utilise achievable milestones without excessive use of opioids. ${ }^{46}$ Indeed, daily function outcomes were deemed important by survey participants with chronic pain, ${ }^{48}$ and should be targets for improvement along with pain control (Box 2).

\section{Recommendations}

- Chronic opioid therapy should be considered only as part of a multidisciplinary pain management

BOX 2. Goals of chronic opioid therapy

Pain control
Restoration of functional status and activities of daily life
Enhanced self-management, reduced use of other health
care resources
Return to work
Improved family and social interactions
Improved sleep and psychological wellbeing
Improved overall quality of life


strategy.

- Opioids should be prescribed only after exhausting other pharmacological and nonpharmacological treatment options.

- Treatment goals acceptable to both patients and their physicians should be set when COT is considered.

- When prescribed, COT should aim to reasonably reduce pain and its associated symptoms, as well as improve functional outcomes.

\section{Patient evaluation and selection}

Prior to starting COT, a comprehensive patient evaluation should be carried out to form a diagnosis, establish the cause of pain, describe pain intensity, and determine a patient's risk profile with the use of opioids. ${ }^{38,46}$ The evaluation informs on the suitability of a patient for COT, and, if the decision to pursue COT is made, provides the foundation for individualising a treatment plan. A thorough history and physical examination with appropriate investigations are essential. The pain complaint should be thoroughly investigated with regard to characteristics, underlying factors, and effects on the patient's functional status. ${ }^{38,46}$ Assessment should include a medical and psychosocial history, including previous medication, general health, family support, and work status. For example, increased use of opioids for pain control prior to spine surgery was found to be associated with worse postoperative outcomes, such as increased demand for opioids after surgery, and decreased incidence of opioid independence 1 year after surgery. ${ }^{49,50}$ This highlights the need for a complete evaluation and screening of each patient prior to opioid use. Evaluation findings may impact subsequent patient counselling and treatment planning.

The rate of problematic opioid use or aberrant drug-related behaviour in patients with CNCP on COT is $11.5 \%{ }^{51}$ Prevalence of substance use disorder among patients with $\mathrm{CNCP}$, with or without opioid use, ranges from $3 \%$ to $48 \% .^{52}$ Because problematic opioid use complicates pain treatment and may cause significant harm, a patient's risk for opioid abuse, misuse, or addiction must be assessed prior to $\mathrm{COT}^{38,46,53,54}$ Screening helps the physician to anticipate the patient's risk of developing aberrant behaviour while on COT. ${ }^{53,54}$ Family and personal history of substance abuse, a history of psychiatric or mood disorders, and younger age have not been validated as predictive of opioid misuse, but have been shown to potentially increase risk..$^{52,55,56}$

The physician can utilise structured clinical interviews and self-reports to elicit these factors. ${ }^{52,56}$ Questionnaires such as the Opioid Risk Tool, which assigns weights to predictive factors of opioid misuse, may be useful. ${ }^{57}$ The presence of apparent predictors of misuse such as a personal or family history of substance abuse or addiction does not necessarily preclude the use of opioids, but may affect structure of therapy (eg closer monitoring, stricter prescription practice) and require additional consultation from specialists, including psychiatrists. ${ }^{54}$ Urine drug screening (UDS) may be a useful aid in detection of latent drug abuse. Every assessment must be thoroughly documented.

According to addiction specialists from the Hong Kong College of Psychiatrists, screening by psychiatrists for suitability of high-risk patients for COT may not be useful, as evidence to support reduced substance abuse risk through conjoint selection by pain specialists and psychiatrists is lacking. There is also inadequate evidence that the future risk of opioid abuse is reduced by treating substance abuse prior to COT; thus, the decision to make this treatment a prerequisite for COT rests on the pain management team (written communication, Clinical Division of Substance Abuse \& Addiction Psychiatry, Hong Kong College of Psychiatrists, 2016). Patients with active substance abuse (opioid, non-opioid, or both) and psychological disturbances may be referred to substance abuse clinics (SACs) in Hong Kong for pre-COT psychiatric treatment (Appendix 1).

\section{Recommendations}

- Patients considered for COT should have a thorough physical, psychological, and social assessment.

- Risk of substance misuse or addiction should also be assessed for appropriate treatment planning.

\section{Prescription of chronic opioids}

\section{Informed consent and documentation}

Guides on COT for CNCP recognise the need for informed consent to explain the benefits, risks, and complications of COT before a trial of opioid therapy, and when the decision to use COT is reached. ${ }^{38,46}$ Consent in the form of a written plan or treatment agreement, or opioid contract, can set expectations between the physician and patient regarding their actions and treatment targets..$^{13,38,46}$ The usefulness of a contract in promoting adherence to a COT regimen lacks evidence, however. Also, use of a contract has underlying ethical issues relating to patient autonomy and the assumption of potential opioid abuse. ${ }^{13,58}$ Nevertheless, if utilised, an agreement should outline information on COT and alternative treatment options, benefits, risks (which include adverse effects, behavioural risks, and medical complications), steps to reach treatment goals, means of monitoring improvements, and conditions for continuing or discontinuing therapy (Appendix 2). ${ }^{13,38,58}$ Specifically, it may include from whom and where the patients should obtain 
their prescription, the number and time of office follow-ups, and expectations on use of UDS. ${ }^{46,58}$ The agreement should be reviewed continually during treatment. ${ }^{46}$

\section{Trial of opioid therapy}

An opioid trial assesses patients' responsiveness to opioids. Dose titration during an opioid trial determines the lowest effective dose with the least or minimal side-effects for an individually tailored programme. ${ }^{59}$ The choice of opioid should be based on factors related to the individual patient, such as previous response to opioids, health status, treatment goals, predicted risks; on medication-related factors, such as availability and pharmacological and adverse effect profiles; and on physician experience and expertise..$^{33,36,59}$ Parenteral forms of opioids are not recommended for an opioid trial due to risk of abuse. ${ }^{33,36}$

Opioids should be titrated slowly, for example, at increments of 10 to $50 \mathrm{mg}$ equivalent per day of a long-acting opioid, until the optimal dose that provides benefit with the least side-effects is attained..$^{33,47,60}$ The optimal dose is suggested to lead to a $30 \%$ pain reduction (based on an 11 -point scale) that does not cause significant adverse effects. ${ }^{33,61} \mathrm{~A}$ trial of therapy may last weeks or months. Duration can be set from 4 to 6 weeks, or up to 90 days in some pain centres. ${ }^{46,47,60}$ The target results and duration of the trial period should be understood and agreed by the patient. ${ }^{46,60}$

\section{Prescription for special concerns}

Driving and work safety are potential concerns when COT is used. Studies have not shown impairment of driving-related activities with opioids, ${ }^{13,62,63}$ but patients should be informed of factors related to opioid use that may cause impairment, including initiating opioids or changing opioid dose, poor sleep, severe pain, and concomitant intake of alcohol or sedating medications..$^{13,33,38}$ Patients should be advised to avoid driving or participating in potentially dangerous activities if they show signs of impaired cognition or psychomotor ability, such as somnolence, poor coordination, or decreased concentration. $^{33,38}$

Pregnant patients or patients planning to get pregnant should be counselled on the risks of COT during pregnancy. Such therapy during pregnancy has been found to be associated with neonatal withdrawal syndrome, poor birth outcome, and certain birth defects. ${ }^{64-66}$ Because of this, COT during pregnancy is not encouraged unless the potential benefits outweigh the risks. ${ }^{38,47}$

\section{Recommendations}

- Informed consent should be obtained before an opioid trial as well as before the start of COT.
Prior to COT, an opioid trial should be conducted to assess patient response and to determine an optimal opioid dose.

- The choice of drugs and initial dosing should be individualised according to the drug profile, patient characteristics and goals, and physician experience.

- Patients on opioids who show signs of impaired cognition or psychomotor activity should be cautioned against driving and other potentially dangerous activities.

- Use of COT during pregnancy is discouraged because opioids may lead to poor birth outcomes.

\section{Monitoring during chronic opioid therapy}

Ongoing assessment and regular monitoring during COT allows physicians to characterise patients who continue to benefit from opioids or who may need changes in their treatment programme. During an opioid trial, the patient is regularly monitored, usually at weekly intervals, to assess the four A's: analgesia, activity, adverse effects, and aberrant behaviour. $^{33,60,67}$ The dose is adjusted based on changes in pain intensity, improvements in daily function, and development of side-effects and of aberrant behaviour. ${ }^{33,35,46}$ Validated pain assessment tools such as the Brief Pain Inventory or the Pain, Enjoyment, and General Activity scale may be used at baseline and at regular intervals thereafter to describe changes in pain relief and function. ${ }^{33,46,47}$ Drug-related behaviour can be monitored through patient interviews, observation, and UDS.

Evidence is lacking on the reliability of UDS in predicting aberrant behaviour, and UDS still needs to be evaluated if it improves clinical outcomes. ${ }^{37}$ Nonetheless, UDS provides important information on adherence to the treatment plan and existence of possible drug misuse when appropriately used with other monitoring tools. Although other biological specimens may be tested, obtaining urine is considered practical and convenient, and results can be obtained within a few days to allow modification of patient care. ${ }^{68}$ Physicians should be aware of limitations in interpreting results and should maintain communication with testing laboratories to resolve any doubts. ${ }^{68}$ In addition, differential diagnoses for each result should be considered, for example, absence of prescribed drug in the urine could indicate non-access to required prescription, or diversion of the prescription. . $^{37,69}$ These considerations should facilitate a discussion with the patient in order to improve care. Prior to the onset of opioid therapy, it is important to educate the patient and specify the objectives of UDS in the treatment agreement to avoid confrontation and uphold a strong physician-patient relationship. ${ }^{69}$

There is no agreement on the frequency of 
UDS, but it should be performed as frequently as necessary according to the patient's risk for misuse, occurrence of aberrant behaviour, and on availability of the test. ${ }^{37,47}$ If aberrant drug behaviour is noticed, the patient may need more intensive monitoring and referral to a pain or substance abuse specialist. ${ }^{47,60}$ Continuation of opioid therapy may be agreed upon by physician and patient if there is note of progress towards the patient's goals as determined from regular monitoring. ${ }^{60}$ If the patient is deemed suitable to continue opioids in the long term after an opioid trial has established a stable dose, monitoring of the four A's is undertaken at regular intervals. ${ }^{60}$ Intervals can be as far apart as 6 months for patients with no risk issues, or as frequent as monthly for those at risk of opioid misuse, or those taking doses near the threshold level. ${ }^{47}$

\section{Recommendations}

- Monitoring during COT should include documentation of pain intensity, level of functioning, presence of adverse events, and adherence to prescribed therapies.

- Validated pain assessment tools may be used at baseline and regularly thereafter to describe changes in pain and function.

\section{Opioid rotation}

Patients who initially responded but have become tolerant despite escalating doses, and those in whom side-effects limit dose increases, may consider an opioid switch or rotation. ${ }^{70}$ Despite the lack of evidence from controlled studies for the clinical effectiveness of opioid rotation, ${ }^{71,72}$ the strategy may be useful based on observed differences in individual responses to various opioids. ${ }^{73}$ This occurrence may be explained by genetic variations in receptor subtypes that modulate drug effects, and that also potentially promote incomplete cross-tolerance among opioids. ${ }^{74}$

Opioid rotation involves selection of a new opioid, determination of its appropriate initial dose, and subsequent titration for a satisfactory balance of efficacy and side-effects. ${ }^{70}$ Use of an equianalgesic table can facilitate estimation of the new drug's initial dose. ${ }^{33,75-78}$ Its dose should approximate the dose of the previous drug (Table $1^{33,75-78}$ ). Drug potencies reflected by the reference table may be underestimated ${ }^{74}$; therefore, experts support an initial automatic reduction in the estimated equianalgesic dose of the new drug by $25 \%$ to $50 \%$ for safety. ${ }^{70}$ If the previous dose was high, a reduction by at least $50 \%$ is recommended by some authors. ${ }^{33}$ Exceptions to this include a switch to methadone, which should use a reduction of $75 \%$ to $90 \%$, and switch to transdermal fentanyl, which does not require a reduction..$^{70}$ This initial computation should be adjusted or retained based on the patient's clinical situation. Subsequent drug titration should be based on this initial dose. ${ }^{70}$

TABLE I. Conversion factors for equianalgesic dose of selected opioids $33,75-78 *$

\begin{tabular}{|c|c|c|c|c|c|}
\hline & Australia $^{75}$ & United Kingdom ${ }^{76}$ & United States $^{77}$ & Canada $^{33}$ & Europe $^{78}$ \\
\hline \multicolumn{6}{|l|}{ Oral preparations } \\
\hline \multicolumn{6}{|l|}{ Swallowed } \\
\hline Morphine (mg/day) & 1 & $\mathrm{NL}$ & 1 & 1 & 1 \\
\hline Oxycodone (mg/day) & 1.5 & $1.5-2$ & $1-2$ & 1.5 & 1.5 \\
\hline Hydromorphone (mg/day) & 5 & $3.5-10$ & 4 & 5 & $\mathrm{NL}$ \\
\hline Codeine (mg/day) & 0.13 & $0.08-0.1$ & $\mathrm{NL}$ & 0.15 & NL \\
\hline Dextropropoxyphene (mg/day) & 0.1 & NL & NL & NL & NL \\
\hline Tramadol (mg/day) & 0.2 & $0.1-0.17$ & NL & NL & NL \\
\hline Tapentadol (mg/day) & 0.4 & $0.3-0.8$ & $\mathrm{NL}$ & NL & NL \\
\hline Methadone (mg/day) & 4.7 & $\mathrm{NL}$ & NL & NL & $\mathrm{NL}$ \\
\hline \multicolumn{6}{|l|}{ Buccal/sublingual } \\
\hline Buprenorphine (mg/day) & 37.5 & 80 & NL & $\mathrm{NL}$ & $\mathrm{NL}$ \\
\hline Fentanyl ( $\mu \mathrm{g} /$ day) & 0.1 & $\mathrm{NL}$ & NL & NL & NL \\
\hline Sufentanil ( $\mu \mathrm{g} /$ day) & 0.5 & $\mathrm{NL}$ & NL & NL & $\mathrm{NL}$ \\
\hline \multicolumn{6}{|l|}{ Transdermal preparations } \\
\hline Buprenorphine $(\mu \mathrm{g} / \mathrm{h})$ & 2.5 & $\mathrm{NL}$ & $\mathrm{NL}$ & $\mathrm{NL}$ & 1.7 \\
\hline Fentanyl $(\mu \mathrm{g} / \mathrm{h})$ & 3 & NL & NL & NL & 2.4 \\
\hline
\end{tabular}

Abbreviation: $\mathrm{NL}=$ value not listed in reference

* Value as listed in the reference 


\section{Recommendations}

- When switching to a new opioid, calculate the equianalgesic dose using a reference equianalgesic table.

- Reduction of the calculated dose is recommended for safety.

- Prior to a new opioid trial, adjust the dose further after reassessment of the patient's clinical situation.

\section{Management of side-effects and problematic opioid use}

Constipation, nausea, headache, and sedation are the most frequently reported opioid side-effects in clinical trials. ${ }^{12}$ Many side-effects reportedly diminish over time, ${ }^{12}$ but some side-effects such as constipation and vomiting may be severe enough to prompt discontinuation from trials. Constipation, in particular, may not diminish and cause significant severe discomfort. ${ }^{79}$ Opioid dose adjustment, opioid rotation, and proactive therapy (eg stool softeners for constipation) are strategies that can minimise severity of adverse effects. ${ }^{21,79}$ Common opioidassociated side-effects should be anticipated and managed appropriately when identified to maintain compliance (Table 2)..$^{33}$

Problematic drug use or aberrant drug behaviour may arise from opioid use. As described previously, patients on COT who are at high risk of opioid misuse or addiction may need additional consultation with addiction experts, and a restructuring of their programme to include frequent, close monitoring. $33,46,47,54$ In addition to patient interviews, proper drug use may be monitored through methods such as regular visits, pill counts, and UDS. ${ }^{80}$ Physicians should attempt to identify the cause of behaviour that suggests the possibility of opioid misuse. It is important to be aware of pseudo-addiction, which apparently exhibits the same compulsive behaviours for opioids as in addiction, but is due to inadequate pain relief from undermedication. ${ }^{81}$

When drug misuse is identified, the patient should undergo a complete re-evaluation for treatment modification. ${ }^{33}$ Repeated, serious aberrant behaviour requires discontinuation of COT and referral to substance abuse specialists for detoxification. ${ }^{33,47}$ Referral channels and treatment through SACs for patients with significant psychological disturbance or addiction features (eg aberrant drug behaviour, other substance abuse such as benzodiazepines) are available in Hong Kong (Appendix 1).

\section{Recommendations}

- Anticipate common side-effects and manage appropriately.

- If problematic drug use is recognised, re-evaluate the patient and modify treatment.

- Discontinue COT if aberrant behaviour is present. Referral to substance abuse specialists is warranted.

\section{Upper dose limit and exit strategy}

The goals of COT should be revisited at regular intervals to see if patients can meet their targets within a defined dose range, determined from the initial daily dose titrated to the lowest effective dose. It is recommended that the upper dose titration limit should not exceed $120 \mathrm{mg}$ of oral morphine or its equivalent, or $200 \mathrm{mg}$ in some centres. ${ }^{33,38,47,60}$ If the daily dose exceeds this limit, a reassessment of the pain condition, potential for misuse, and need for more frequent monitoring is warranted. ${ }^{33,38}$ Indications for discontinuation include no change or improvement in therapeutic goals despite escalating doses, intolerance to side-effects, and persistence of aberrant behaviour. If the decision to discontinue opioids is reached, the opioid should be tapered to avoid withdrawal problems. ${ }^{33,46,47,60}$

The tapering plan is variable, but generally, a reduction of $10 \%$ per week from the original dose is well tolerated. ${ }^{33,47,60} \mathrm{~A}$ faster or slower rate may be suitable depending on the patient's situation. Physicians should monitor patients for changes in pain and for the appearance of side-effects, withdrawal symptoms, and behavioural issues. These concerns should be properly managed. In some cases, a referral to the appropriate specialists may be warranted. Likewise, patients who fail to benefit from COT and who need discontinuation may be referred to SACs in Hong Kong for detoxification and rehabilitation services (written communication, Clinical Division of Substance Abuse \& Addiction Psychiatry, Hong Kong College of Psychiatrists, 2016).

TABLE 2. Opioid-associated side-effects and complications ${ }^{33}$

\begin{tabular}{lll}
\hline Common side-effects & Long-term complications & Specific drug effects \\
\hline $\begin{array}{l}\text { Constipation, nausea, vomiting, } \\
\text { drowsiness, dizziness, sedation, dry } \\
\text { mouth, dry skin, pruritus, respiratory } \\
\text { depression }\end{array}$ & $\begin{array}{l}\text { Constipation, physical dependence, tolerance, } \\
\text { addiction, opioid-induced hyperalgesia, cognitive } \\
\text { dysfunction, impaired immunity, reduced sexual } \\
\text { function and infertility }\end{array}$ & $\begin{array}{l}\text { Methadone can produce prolonged QT interval } \\
\text { corrected for heart rate } \\
\text { Hydrocodone may cause sensorineural hearing loss }\end{array}$ \\
\hline
\end{tabular}




\section{Recommendations}

- Chronic opioid therapy should be stopped if patients experience no progress towards treatment goals, experience intolerable sideeffects, or are engaged in repeated aberrant drugrelated behaviours.

- Opioids should be tapered to avoid withdrawal.

\section{Conclusion}

Strong opioids play a role in the multimodal management of CNCP. They may be appropriate for selected patients despite insufficient evidence of effectiveness. Opioid therapy is potentially associated with common side-effects and significant harm; thus, careful patient selection by a thorough patient evaluation prior to treatment, and careful dose titration and monitoring during initiation and long-term therapy, are all recommended steps for rational opioid use in CNCP. Whenever opioid is prescribed for chronic pain management, it should be started with a low dose and titrated slowly, as well as maintained for the shortest possible time.

\section{Appendices}

Additional material related to this article can be found on the HKMJ website. Please go to <http:// www.hkmj.org >, and search for the article.

\section{Acknowledgements}

We would like to thank the Clinical Division of Substance Abuse \& Addiction Psychiatry, Hong Kong College of Psychiatrists for their advice and opinions.

\section{Declaration}

All authors are members of the working group for Guideline for Chronic Opioid Therapy in Chronic Noncancer Pain, Hospital Authority Multidisciplinary Committee on Pain Medicine, Hospital Authority, Hong Kong. All authors have disclosed no conflicts of interest.

\section{References}

1. Merskey $\mathrm{H}$, Bogduk $\mathrm{N}$, editors. International Association for the Study of Pain. Task Force on Taxonomy. Classification of chronic pain: descriptions of chronic pain syndromes and definitions of pain terms. 2nd ed. Seattle: IASP Press; 2002.

2. Gatchel RJ, Peng YB, Peters ML, Fuchs PN, Turk DC. The biopsychosocial approach to chronic pain: scientific advances and future directions. Psychol Bull 2007;133:581624.

3. Ng KF, Tsui SL, Chan WS. Prevalence of common chronic pain in Hong Kong adults. Clin J Pain 2002;18:275-81.

4. Wong WS, Fielding R. Prevalence and characteristics of chronic pain in the general population of Hong Kong. J
Pain 2011;12:236-45.

5. Vallejo R, Barkin RL, Wang VC. Pharmacology of opioids in the treatment of chronic pain syndromes. Pain Physician 2011;14:E343-60.

6. World Health Organization. WHO's cancer pain ladder for adults. Available from: http://www.who.int/cancer/ palliative/painladder/en/. Accessed 28 Jul 2015.

7. Manchikanti L, Vallejo R, Manchikanti KN, Benyamin RM, Datta S, Christo PJ. Effectiveness of long-term opioid therapy for chronic non-cancer pain. Pain Physician 2011;14:E133-56.

8. Chou R, Turner JA, Devine EB, et al. The effectiveness and risks of long-term opioid therapy for chronic pain: a systematic review for a National Institutes of Health Pathways to Prevention Workshop. Ann Intern Med 2015;162:276-86.

9. Kalso E, Edwards JE, Moore RA, McQuay HJ. Opioids in chronic non-cancer pain: systematic review of efficacy and safety. Pain 2004;112:372-80.

10. Furlan AD, Sandoval JA, Mailis-Gagnon A, Tunks E. Opioids for chronic noncancer pain: a meta-analysis of effectiveness and side effects. CMAJ 2006;174:1589-94.

11. Papaleontiou M, Henderson CR Jr, Turner BJ, et al. Outcomes associated with opioid use in the treatment of chronic noncancer pain in older adults: a systematic review and meta-analysis. J Am Geriatr Soc 2010;58:1353-69.

12. Noble M, Treadwell JR, Tregear SJ, et al. Long-term opioid management for chronic noncancer pain. Cochrane Database Syst Rev 2010;(1):CD006605.

13. Chan BK, Tam LK, Wat CY, Chung YF, Tsui SL, Cheung CW. Opioids in chronic non-cancer pain. Expert Opin Pharmacother 2011;12:705-20.

14. Moore RA, McQuay HJ. Prevalence of opioid adverse events in chronic non-malignant pain: systematic review of randomised trials of oral opioids. Arthritis Res Ther 2005;7:R1046-51.

15. Noble M, Tregear SJ, Treadwell JR, Schoelles K. Long-term opioid therapy for chronic noncancer pain: a systematic review and meta-analysis of efficacy and safety. J Pain Symptom Manage 2008;35:214-28.

16. Dhalla IA, Mamdani MM, Sivilotti ML, Kopp A, Qureshi O, Juurlink DN. Prescribing of opioid analgesics and related mortality before and after the introduction of long-acting oxycodone. CMAJ 2009;181:891-6.

17. Okie S. A flood of opioids, a rising tide of deaths. N Engl J Med 2010;363:1981-5.

18. Edlund MJ, Martin BC, Russo JE, DeVries A, Braden JB, Sullivan MD. The role of opioid prescription in incident opioid abuse and dependence among individuals with chronic noncancer pain: the role of opioid prescription. Clin J Pain 2014;30:557-64.

19. Vestergaard P, Rejnmark L, Mosekilde L. Fracture risk associated with the use of morphine and opiates. J Intern Med 2006;260:76-87.

20. Smith HS, Elliott JA. Opioid-induced androgen deficiency (OPIAD). Pain Physician 2012;15(3 Suppl):ES145-56.

21. Inturrisi CE. Clinical pharmacology of opioids for pain. Clin J Pain 2002;18(4 Suppl):3S-13S.

22. Ersek M, Cherrier MM, Overman SS, Irving GA. The cognitive effects of opioids. Pain Manag Nurs 2004;5:7593.

23. Roy S, Loh HH. Effects of opioids on the immune system. Neurochem Res 1996;21:1375-86. 
24. Lee M, Silverman SM, Hansen H, Patel VB, Manchikanti L. A comprehensive review of opioid-induced hyperalgesia. Pain Physician 2011;14:145-61.

25. Tompkins DA, Campbell CM. Opioid-induced hyperalgesia: clinically relevant or extraneous research phenomenon? Curr Pain Headache Rep 2011;15:129-36.

26. Pain \& Policy Studies Group. Global opioid consumption, 2013. Available from: http://www.painpolicy.wisc.edu/ global. Accessed 1 Aug 2015.

27. Pain \& Policy Studies Group. Opioid consumption mapsMorphine equivalence (ME), mg/capita, 2014. Available from: https://ppsg.medicine.wisc.edu. Accessed 11 Oct 2015.

28. Pain \& Policy Studies Group. Consumption data at-aglance: Hong Kong SAR, 2012. Available from: http:// www.painpolicy.wisc.edu/country/profile/hong-kong-sar. Accessed 1 Aug 2015.

29. United Nations Office on Drugs and Crime. World Drug Report 2008. Available from: http://www.unodc.org/ unodc/en/data-and-analysis/WDR-2008.html. Accessed 7 Jan 2016.

30. Drug Office, Department of Health, The Government of Hong Kong Special Administrative Region. Registered pharmaceutical products. Available from: http://www. drugoffice.gov.hk/eps/do/en/consumer/reg_pharm_ products/index.html. Accessed 11 Oct 2015.

31. Ho KY, Chua NH, George JM, et al. Evidence-based guidelines on the use of opioids in chronic non-cancer pain-a consensus statement by the Pain Association of Singapore Task Force. Ann Acad Med Singapore 2013;42:138-52.

32. Manchikanti L, Abdi S, Atluri S, et al. American Society of Interventional Pain Physicians (ASIPP) guidelines for responsible opioid prescribing in chronic non-cancer pain: Part 2-guidance. Pain Physician 2012;15(3 Suppl):67S$116 \mathrm{~S}$.

33. Canadian guideline for safe and effective use of opioids for chronic non-cancer pain. Canada: National Opioid Use Guideline Group (NOUGG); 2010. Available from: http:// nationalpaincentre.mcmaster.ca/opioid/. Accessed 9 Aug 2016.

34. American College of Occupational and Environmental Medicine. Guidelines for chronic use of opioids. Available from: http://www.acoem.org/Guidelines_Opioids.aspx. Accessed 25 Nov 2014.

35. Australian and New Zealand College of Anaesthetists Faculty of Pain Medicine. Recommendations regarding the use of opioid analgesics in patients with chronic non-cancer pain. Available from: http://www.fpm.anzca. edu.au/resources/professional-documents/documents/ PM1\%202010.pdf. Accessed 25 Nov 2014.

36. British Pain Society. Opioids aware: A structured approach to prescribing. Faculty of Pain Medicine, Royal College of Anaesthetists. Available from: https://www.rcoa.ac.uk/ faculty-of-pain-medicine/opioids-aware/structuredapproach-to-prescribing. Accessed 9 Aug 2016.

37. Chou R, Fanciullo GJ, Fine PG, et al. Clinical guidelines for the use of chronic opioid therapy in chronic noncancer pain. J Pain 2009;10:113-30.

38. Cheung CW, Qiu Q, Choi SW, Moore B, Goucke R, Irwin M. Chronic opioid therapy for chronic non-cancer pain: a review and comparison of treatment guidelines. Pain Physician 2014;17:401-14.
39. Von Korff M, Saunders K, Thomas Ray G, et al. De facto long-term opioid therapy for noncancer pain. Clin J Pain 2008;24:521-7.

40. International Association for the Study of Pain. Pain treatment services. Available from: http://www.iasppain.org/Education/Content.aspx? ItemNumber $=1381$. Accessed 9 Sep 2015.

41. Gatchel RJ, McGeary DD, McGeary CA, Lippe B. Interdisciplinary chronic pain management: past, present, and future. Am Psychol 2014;69:119-30.

42. Jeffrey MM, Butler M, Stark A, Kane RL. Multidisciplinary pain programs for chronic noncancer pain: Technical brief No. 8. AHRQ Publication No. 11-EHC064-EF. Rockville, MD: Agency for Healthcare Research and Quality; Sep 2011. Available from: http://www.ncbi.nlm.nih.gov/books/ NBK82511/pdf/Bookshelf_NBK82511.pdf. Accessed 9 Aug 2016.

43. Gatchel RJ, Okifuji A. Evidence-based scientific data documenting the treatment and cost-effectiveness of comprehensive pain programs for chronic nonmalignant pain. J Pain 2006;7:779-93.

44. Guzmán J, Esmail R, Karjalainen K, Malmivaara A, Irvin E, Bombardier C. Multidisciplinary rehabilitation for chronic low back pain: systematic review. BMJ 2001;322:1511-6.

45. Turk DC. Clinical effectiveness and cost-effectiveness of treatments for patients with chronic pain. Clin J Pain 2002;18:355-65.

46. Federation of State Medical Boards. Model policy on the use of opioid analgesics in the treatment of chronic pain, July 2013. Available from: http://www.fsmb.org/Media/ Default/PDF/FSMB/Advocacy/pain_policy_july2013.pdf. Accessed 9 Aug 2016.

47. Agency Medical Directors' Group. AMDG 2015 Interagency guidelines on prescribing opioids for pain. Available from: http://www.agencymeddirectors.wa.gov/ guidelines.asp. Accessed 11 Aug 2015.

48. Turk DC, Dworkin RH, Revicki D, et al. Identifying important outcome domains for chronic pain clinical trials: an IMMPACT survey of people with pain. Pain 2008;137:276-85.

49. Lee D, Armaghani S, Archer KR, et al. Preoperative opioid use as a predictor of adverse postoperative self-reported outcomes in patients undergoing spine surgery. J Bone Joint Surg Am 2014;96:e89.

50. Armaghani SJ, Lee DS, Bible JE, et al. Preoperative opioid use and its association with perioperative opioid demand and postoperative opioid independence in patients undergoing spine surgery. Spine (Phila Pa 1976) 2014;39:E1524-30.

51. Fishbain DA, Cole B, Lewis J, Rosomoff HL, Rosomoff RS. What percentage of chronic nonmalignant pain patients exposed to chronic opioid analgesic therapy develop abuse/addiction and/or aberrant drug-related behaviors? A structured evidence-based review. Pain Med 2008;9:44459.

52. Morasco BJ, Gritzner S, Lewis L, Oldham R, Turk DC, Dobscha SK. Systematic review of prevalence, correlates, and treatment outcomes for chronic non-cancer pain in patients with comorbid substance use disorder. Pain 2011;152:488-97.

53. Højsted J, Sjøgren P. Addiction to opioids in chronic pain patients: a literature review. Eur J Pain 2007;11:490-518.

54. Atluri S, Akbik H, Sudarshan G. Prevention of opioid abuse 
in chronic non-cancer pain: an algorithmic, evidence based approach. Pain Physician 2012;15(3 Suppl):ES177-89.

55. Edlund MJ, Steffick D, Hudson T, Harris KM, Sullivan M. Risk factors for clinically recognized opioid abuse and dependence among veterans using opioids for chronic non-cancer pain. Pain 2007;129:355-62.

56. Turk DC, Swanson KS, Gatchel RJ. Predicting opioid misuse by chronic pain patients: a systematic review and literature synthesis. Clin J Pain 2008;24:497-508.

57. Webster LR, Webster RM. Predicting aberrant behaviors in opioid-treated patients: preliminary validation of the Opioid Risk Tool. Pain Med 2005;6:432-42.

58. Arnold RM, Han PK, Seltzer D. Opioid contracts in chronic nonmalignant pain management: objectives and uncertainties. Am J Med 2006;119:292-6.

59. Geppetti P, Benemei S. Pain treatment with opioids: achieving the minimal effective and the minimal interacting dose. Clin Drug Investig 2009;29 Suppl 1:3S-16S.

60. Department of Health, Government of Western Australia. Quick clinical guideline for the use of opioids in chronic non-malignant pain. Available from: http://www. hnehealth.nsw.gov.au/Pain/Pages/Health-professionalresources.aspx. Accessed 28 Jul 2015.

61. Farrar JT, Young JP Jr, LaMoreaux L, Werth JL, Poole RM. Clinical importance of changes in chronic pain intensity measured on an 11-point numerical pain rating scale. Pain 2001;94:149-58.

62. Fishbain DA, Cutler RB, Rosomoff HL, Rosomoff RS. Are opioid-dependent/tolerant patients impaired in drivingrelated skills? A structured evidence-based review. J Pain Symptom Manage 2003;25:559-77.

63. Engeland A, Skurtveit S, Mørland J. Risk of road traffic accidents associated with the prescription of drugs: a registry-based cohort study. Ann Epidemiol 2007;17:597602.

64. Hadi I, da Silva O, Natale R, Boyd D, Morley-Forster PK. Opioids in the parturient with chronic nonmalignant pain: a retrospective review. J Opioid Manag 2006;2:31-4.

65. Broussard CS, Rasmussen SA, Reefhuis J, et al. Maternal treatment with opioid analgesics and risk for birth defects. Am J Obstet Gynecol 2011;204:314.e1-11.

66. Fajemirokun-Odudeyi O, Sinha C, Tutty S, et al. Pregnancy outcome in women who use opiates. Eur J Obstet Gynecol Reprod Biol 2006;126:170-5.

67. Passik SD, Kirsh KL, Whitcomb L, et al. A new tool to assess and document pain outcomes in chronic pain patients receiving opioid therapy. Clin Ther 2004;26:55261.

68. Gourlay DL, Heit HA, Caplan YH. Urine drug testing in clinical practice: the art and science of patient care. 6th ed. Baltimore, MD: John Hopkins University School of Medicine; Aug 2015. Available from: http://www. udtmonograph6.com/view-monograph.html. Accessed 23 Aug 2016.

69. Peppin JF, Passik SD, Couto JE, et al. Recommendations for urine drug monitoring as a component of opioid therapy in the treatment of chronic pain. Pain Med 2012;13:886-96.

70. Fine PG, Portenoy RK, Ad Hoc Expert Panel on Evidence Review and Guidelines for Opioid Rotation. Establishing "best practices" for opioid rotation: conclusions of an expert panel. J Pain Symptom Manage 2009;38:418-25.

71. Quigley C. Opioid switching to improve pain relief and drug tolerability. Cochrane Database Syst Rev 2004;(3):CD004847.

72. Mercadante S, Bruera E. Opioid switching: a systematic and critical review. Cancer Treat Rev 2006;32:304-15.

73. Pasternak GW. Molecular biology of opioid analgesia. J Pain Symptom Manage 2005;29(5 Suppl):2S-9S.

74. Knotkova H, Fine PG, Portenoy RK. Opioid rotation: the science and the limitations of the equianalgesic dose table. J Pain Symptom Manage 2009;38:426-39.

75. Nielsen S, Degenhardt L, Hoban B, Gisev N. Comparing opioids: a guide to estimating oral morphine equivalents (OME) in research. Technical Report No. 329. Sydney: National Drug and Alcohol Research Centre, University of New South Wales; 2014. Available from: https://ndarc. med.unsw.edu.au/resource/comparing-opioids-guideestimating-oral-morphine-equivalents-ome-research. Accessed 24 Mar 2016.

76. UK Medicines Information (UKMi). Medicines Q\&As: Q\&A 42.7: What are the equivalent doses of oral morphine to other oral opioids when used as analgesics in adult palliative care? Available from: http://www.ukmi.nhs.uk/ activities/medicinesQAs/default.asp. Accessed 24 Mar 2016.

77. Lexicomp. Drug information handbook: a clinically relevant resource for all healthcare professionals. 23rd ed. Ohio: Lexicomp; 2014.

78. Mercadante S, Caraceni A. Conversion ratios for opioid switching in the treatment of cancer pain: a systematic review. Palliat Med 2011;25:504-15.

79. Benyamin R, Trescot AM, Datta S, et al. Opioid complications and side effects. Pain Physician 2008;11(2 Suppl):105S-120S.

80. Sehgal N, Manchikanti L, Smith HS. Prescription opioid abuse in chronic pain: a review of opioid abuse predictors and strategies to curb opioid abuse. Pain Physician 2012;15(3 Suppl):ES67-92.

81. Weissman DE, Haddox JD. Opioid pseudoaddiction-an iatrogenic syndrome. Pain 1989;36:363-6. 